\title{
EVALUATION OF KNOWLEDGE EFFECTIVENESS IN THE REAL ECONOMY
}

Alzhanat Suleymankadieva, Saint-Petersburg State Economic University, saljanat@mail.ru

In the present investigation, we created a methodology for the evaluation of knowledge effectiveness of Russian economy. It helps us to assess the real level of readiness of Russian real economy to move to the Knowledge Economy. We evaluated the innovative development of the Russian economy using the following indices: the growth of inventive activity, the share of modern manufacturing and service sector in the GDP, the changes in the nature of social behaviour, and the well functioning of the market mechanism. The objective of the analysis was to evaluate the conformance of the Russian economy, in a special reference, to the European Knowledge Economy. We have defined sub indexes which were normalized between zero and one. We evaluated the knowledge effectiveness of Russian economy using European approach for Knowledge Economy. In order to obtain the complex Index of Knowledge Effectiveness, we used the statistical methods to summarize weighted knowledge effectiveness sub indexes by formula $V_{m}=\Sigma \varphi_{i} e_{i m}$. Results showed that this index totaled 0.28 at the maximum possible value of 1 . This indicates significant need to create a new effective economic model with different management.

JEL classification numbers: O11, O47, D83, DOI: 10.12955/cbup.2013.22

Keywords: evaluation, knowledge effectiveness, real economy

\section{Introduction}

In the new, modern economic conditions, when the world changes, the most relevant knowledge is how to deal with intensive accumulation and implementation of new technologies, innovations, abilities and skills. Continuous creation, storage, processing, transmission and use of knowledge require a new methodological approach or methods for estimating the effectiveness of knowledge in each phase of the Triad "Permanent Scientific System (LSS) - Continuing Education System (LES) Real Economic System (RES)."

There are available many methodological approaches and methods for the evaluation of intellectual capital (Zeng et al., 2007; Zheng et al., 2009). These include: (1) the method of the market rate and the carrying value of the company (market-to-book ratio) and Tobin coefficient (Q), (2) the assessment methodology based on economy, namely 86 standardized parameters.

It is known as a methodology for evaluating knowledge. There are (3) methods for assessing human capital, (4) methods of estimating the market value of the company, (5) the parametric method estimation of knowledge, and (6) methods of assessment of intellectual capital, which was included in the cost of "markets" and profits approaches (including methods of estimating the cost of information security. But they all have their advantages and disadvantages. First, in the literature there is no 
evidence that this method provides required accuracy of Knowledge (Project) level estimates. Secondly, we must strictly abide by the rating methodology and the accuracy of estimated results that cannot be achieved, especially in the early stages of the project, when there is a lack of information. In this case, we can have erroneous results.

Therefore, we determined the following objective of this article - to create a methodology of knowledge effectiveness assessment in Russian real economic conditions. We studied the knowledge, processed and translated them from the LES the RES.

This approach allows: (1) to evaluate the potential of the LES, "knowledge" and the permanent capacity of LES science is received. LES can accumulate, transform and translate into RES in order to execute them into innovative products and services (2) to use the knowledge that the innovative economy requires today, and (3) to do a comprehensive assessment both in terms to comply with the LES requirements of modern knowledge society (e. g. market structure, dynamics, social development and innovative changes) and a multi-level (or scales) of knowledge spillovers that can influence the real economy. These external effects, the degree of compliance (or non-compliance) of the RES are requirements of the European Knowledge Economy (KE).

\section{The methodological approach to evaluate the knowledge effectiveness}

In this study, a methodology is created to assess the effectiveness of the knowledge that is used in real economic conditions. This knowledge has been accumulated in LES before. Here, we have developed a methodology that allows us to assess the actual level of readiness of the Russian economy to move into the Knowledge Economy. Therefore, we estimated the development of economic sectors: (1) the structural and territorial development, (2) market development, (3) social development, (4) development dynamics (acceleration) (5) the development of innovations. According to the requirements of real KE, Russian economy has been using the complex and aggregate Index of Knowledge Effectiveness (IKE).

All of these areas were evaluated using five groups in line with respect to the indicators. First group structural and territorial development. We have estimated using the following parameters: the level of development of economy's sectors, the level of economy's technological development and the compliance with the structural development of the Russian economy compared to the European level of knowledge economy.

Market development of Russian economy function used indicators: observance of international business development in Russia, the level of Russia's GDP, the level of expenditures of the State for the development of Russian education with the European level, the overall productivity and investment in $R \& D$.

The social level of Russian development was estimated using the qualification of Russian specialists, the accessibility of the higher education, employment in the Russian economy, the UN human development index, the leisure index (the index was to characterize the growth rate of social return on investment in human capital - per capita index characterizes the proportion of population in the field of lifelong learning (age of participants ranging between $25-64$ )).

Dynamics of development, we used indexes to characterize intensity of the high-tech sectors of the economy, the intensity of job search revenue from individuals, the speed of Information and Communication Technology (ICT). We have evaluated the innovative development of the Russian 
economy using the following indices: the growth of inventive activity, the share of innovative products and services in total exports of goods and services, the proportion of expenditure for technological innovation in the total volume of goods and services by organizations in R\&D. All these individual indicators were grouped ranged from zero to one.

On one hand, specifics of knowledge represent a factor of production, as it is in the creation of new knowledge (e.g. knowledge produces new knowledge) and help to increase the production of new products and services, but, on the other hand, can generate significant externalities that affect the real economic conditions, serving the new knowledge producing process.

D. Tsiplakova is of the opinion that new knowledge contribute to the development and implementation (heavy use) of new knowledge (Tsiplakova, 2010). It contributes to: (a) scientific and technological progress and intensive development of the economy that actively uses new knowledge, (b) emergence of effective factors of production and development, (c) the improvement of ICT and greatly accelerates the translation of information and communication between agents by simplifying the processes, (d) introduction of new facilities and more efficient equipment, improves the quality and accuracy of operations to reduce the time functions. Otherwise, knowledge as a factor of production increases the level of socio-economic system, so it has effects in the intensive development of the economy. This fact reinforces the backlog of countries that do not adopt or do not use a new technology.

The evaluation of the effectiveness of implementation of new knowledge in the real economy due to the specificity of the actual economic conditions in Russia today can be explained and justified by following reasons: (1) presence of specific characteristics of knowledge as a socio-economic phenomenon: the cumulative nature that is unique, powerful and difficult to manage and even unpredictable knowledge sluggish character, multiplicativeness, synergy effect, etc. Therefore, the examination of the impact of knowledge on the real economy from this point of view is reasonable, (2) the absence of intellectual property rights on knowledge in Russia as a resource and consumer goods (because the price does not reflect the value of its alternative use, it does not reflect missed opportunities), (3) the high level of corruption in the highest echelons of government and the inert nature of laws and regulations activities of knowledge management, (4) lack of a proper state strategy and economic policies on the forecast, planning, motivation, management, coordination of knowledge management system, lifelong education and the real economy, (5) the unequal distribution of knowledge in different regions due to the geographical concentration of economic systems which actively disseminate knowledge, ideas, skills and experiences. This fact makes a failure of knowledge that is transferred from the LES to RES. There are not dependent on the economic structure and the requirements of the industrial areas and economic regions in the knowledge economy in general. Requirements of the actual level of the knowledge economy are not realized. For example, the most important sources of knowledge sectors in Russia are mainly engaged in the research centers, such as Moscow, St. Petersburg, Novosibirsk and other major cities focused on science. As a result, innovative organizations actively use new knowledge, spread close to them, and concentrate scientific activities in these regions. This shows that in some regions and sectors of the economy develop rapidly and intensely, but others have a large backlog of science cities in perspective. This phenomenon is due to structural and spatial disparities in the development of industries and regions of Russia, (6) progressive phenomenon of 'brain drain', which is performed with the "knowledge drain" of Russia in the world. Thus, the massive exodus of Russian scientists managed the process of knowledge production and application intensively abroad. Consequently, this means that the level of Russia's economic development will be significantly less than the "standard" in the knowledge economy of 
developed countries (USA, Japan, Germany, United Kingdom of Great Britain, the OECD countries), and (7) the low human development index, mainly caused by poor access to education, the low quality of life expectancy and low per capita income and a strong differentiation in the regional context.

It should be noted that the external effects can be both positive and negative. Externalities can be positive as new knowledge, which is reflected in the scientific system of RES. It is used in production, in new products and services, more efficient machinery and equipment, etc. Embodied knowledge materializes a new level of economic development; it has a positive impact on the productivity of the factors of production. In this case, the RES is the rate of economic growth of knowledge and the maximum amount of their differences will be minimal.

On the other hand, knowledge spillovers can be negative if the level of development of RES differs and lag from the level of development of the KE. This situation will occur if knowledge is embodied in new types of products and services that do not lead to intensive growth of productivity factors and do not raise the level of real economy. This situation can be observed when we see the simultaneous coexistence of several technology options: V., IV. and III. generation of technology in different sectors of the economy, including the education sector. In this case, we can identify situations: (1) if the level of new knowledge of LES translated to the RES is not high and knowledge which was used in the real economy does not contribute to the production of productivity factors; (2) when the novelty of the knowledge, ideas and skills of LES transferred to the RES is very high, but the real economy is not willing to accept and use them quickly. It should be noted that the period of the lag of LES level into RES in Russia causes imbalance in the structure and dynamics of the main socio-economic indicators at the macro and mezoeconomic levels and delay the economics from advanced and innovative knowledge economy. In this situation, the external effects have a negative effect on lifelong learning and the real economic system as a whole.

In this study the influence of external effects can be determined as an index EKE. We consider knowledge translated from lifelong education and used in real economy. In the triad "LSS - LES RES" the lifelong education, as an intermediate element, transforms and translates knowledge into the real economy, where they are implemented in new products and services. Estimation of the effects' efficiency can show the efficiency of transferring and using the knowledge on different levels of scale (on macro-, mezo- and microeconomic level and on the individual level) as indicator of: lag of RES of Russia from the advanced modern world KE.

\section{Evaluation of external knowledge effects influence}

In according to the aim of this article, we investigated the fragment "LES - RES" from triad "LSS LES - RES". The study deals with estimation of RESs' ability to receive and use the new knowledge and skills. Furthermore, we determined the following main research phases of investigation of external effects of KE.

1. At this stage, the following main groups of knowledge effects were identified: (a) effects of accordance of structural and regional development on high developed European countries $\left(e_{1}\right)$ which tracks the level of compliance of LES with the requirements of knowledge economy, for example, the sectoral structure of Russian economy, and the needs of the professional structure, etc.; (b) effects of market accordance $\left(e_{2}\right)$. Such characteristics are tracked as the rate of productivity growth, the level of spending on training, (for example, on training of one student or one employee), economic growth rate, etc.; (c) effects of social changes $\left(e_{3}\right)$. In this group, the effects are considered, for example, the 
level of stability of the professional staff, the human development index, the amount of leisure time, access to education, per capita income, social returns on human capital, etc. (d) dynamics' effects $\left(e_{4}\right)$, for example, lag of professional updates, the rate of accumulation of human capital, etc.; (e) effect of innovative changes $\left(e_{5}\right)$ - effects associated with creation and innovation features of the economy (for example, the number of patents and inventions, the results of scientific activity in the research sector of economy, the share of researchers in education system, spatially in high education system, etc.

2. The knowledge externalities (effects) and their individual indicators have been considered with the scale level. Four levels of effects were identified: macro-, mezo-, microeconomic, and individual levels. The knowledge influences each level. It was assessed by the growth rate of main socioeconomic indicators. We determined the structural and territorial compliance of real economic system with the advanced knowledge economy. Then we considered others, such as: market, social, dynamic and innovation development. The influence of External knowledge effects at each level of economy is shown with the help of individual indicators. We determined them as equation (1):

$$
e_{i}=\Sigma \beta_{i} e_{i j}
$$

Where $\beta_{i}$ - a weighted coefficient of indicator $\left(e_{i j}\right) ; i$ - the level of impact of knowledge effect on economy $(i=1,4) ; j$ - the quantity of individual indicators influence the economy $(j=1,32)$.

3. The knowledge effectiveness can be represented by the following vectors of externalities which influence the economy as formulas (2-6):

$$
\begin{aligned}
& \left\{V_{e 1}(j) \mid \forall j \in(1, \ldots, 6)\right\} \\
& \left\{V_{e 2}(j) \mid \forall j \in(1, \ldots, 6)\right\} \\
& \left\{V_{e 3}(j) \mid \forall j \in(1, \ldots, 7)\right\} \\
& \left\{V_{e 4}(j) \mid \forall j \in(1, \ldots, 7)\right\} \\
& \left\{V_{e s}(j) \mid \forall j \in(1, \ldots, 6)\right\},
\end{aligned}
$$

Where $V e_{1}, V e_{2}, V e_{3}, V e_{4}$ and $V e_{5}-$ vectors of different external knowledge effects. These five groups of externalities can influence the four levels of economy (the macro-, mezo-, micro- and individual levels).

4. Here we determined that the five types of external factors of knowledge economy can have their impact on macro-, mezo-, micro- and individual level. We formed vectors of factors which influenced these four levels of Russian economy. Indicators of macroeconomic level are denoted with index " $m$ " (for example), effects of mezoeconomic level are denoted by the subscript " $r$ ", the microeconomic (organizational) level - by index " $o$ ", and, at last, individual level - by " $l$ ". For example, the indicator which shows the effects of structural and territorial changes can be marked as: $e_{1 m}, e_{l r}, e_{l o}, e_{l l}$.

5. We could determine the aggregated indicators for every effect and for every level of economy. They were given in a comparable and normalized form. We used the expert method of evaluation, where all individual indicators vary from zero to one. All these indicators were weighed. In this study, it was 
assumed that all of them had a same importance $\left(\beta_{i}\right)$. After, all of these individual indicators were aggregated.

6. We constructed the vectors' system of effects which influence the macro-, mezo-, micro- and individual level of economy. We can show this system of indicators using following formulas (7-10). This system was organized from multilevel point of influence.

$$
\begin{aligned}
& \left\{V_{m}(i) \mid \forall i \in(1, \ldots, 24)\right\}, \\
& \left\{V_{r}(i) \mid \forall i \in(1, \ldots, 25)\right\}, \\
& \left.\left\{V_{o} i j\right) \mid \forall i \in(1, \ldots, 7)\right\}, \\
& \left\{V_{l}(i) \mid \forall i \in(1, \ldots, 5)\right\},
\end{aligned}
$$

Where $V(i)$ - vector of indices which is formed on the multilevel point of view (or scale level);

$i$ - number of indicators which were involved in the formation of aggregated indicators of effects corresponding to each level.

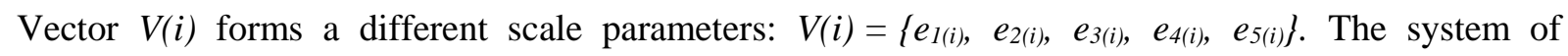
aggregates can be represented in the matrix form (11).

$$
E=\left(\begin{array}{cccc}
\overline{e_{1 m}} & e_{1 r} & e_{1 o} & e_{1 l} \\
e_{2 m} & e_{2 r} & e_{2 o} & e_{2 l} \\
e_{3 m} & e_{3 r} & e_{3 o} & e_{3 l} \\
e_{4 m} & e_{4 r} & e_{4 o} & e_{4 l} \\
e_{5 m} & e_{5 r} & e_{5 o} & e_{5 l}
\end{array}\right)
$$

The matrix E (formula 11) shows vertical aggregates (vectors) that characterize the impact of different groups of external effects; they have a multilevel impact on the economy. Thus we can get integrated indicators which influence the macroeconomic level of Russia $\left(V_{m}\right)$, mezoeconomic level (or regional level) $\left(V_{r}\right)$, microeconomic level (organizational level) $\left(V_{O}\right)$ and individual level (individuals) $\left(V_{l}\right)$. The value of each of these indicators can be defined as the sum of the weighted vertical aggregates $\left(\Sigma \varphi_{i} V_{i}\right)$. It shows the accumulative effect of all external factors of macro economy. The sum of weights equal to: $\varphi=\Sigma \varphi_{i}=1.0$.

7. The accordance of these indexes to normative their values (to requirements of knowledge economy) determines the effectiveness of LES in the triad "LSS - LES - RES".

Horizontally, we could determine the degree of influence of each effect at all levels of economy simultaneously (the macro-, mezo-, micro- and individual level). These effects can be aggregated and described horizontally as a sub index of structural and territorial effects $\left(e_{1}\right)$, sub index of market 
effects $\left(e_{2}\right)$, sub index of social effects $\left(e_{3}\right)$, sub index of dynamic effects $\left(e_{4}\right)$ and the sub index of innovation effects $\left(e_{5}\right)$. The study carried out was based on both primary and secondary data. The primary data were collected from respondents that were questioned. These data cannot be obtained from statistic reviews, for example, such individual indexes as index characterizing the accessibility of education at the economy or index characterizing leisure time of individuals, etc. These indicators were used for determination of the index of social effects $\left(e_{3}\right)$. The secondary data were received from statistic journals, websites, reviews, monographs, etc. (Regions of Russia. Socio-economic indicators, 2011; Suleymankadieva, 2012). The primary data ware obtained from teachers and students of two universities: Saint-Petersburg State University of Economics and Finance \& Saint-Petersburg State University of Engineering and Economics and from employers. Every index was also defined as the sum of weighted horizontal aggregates $\left(\Sigma \varphi_{i} e_{i}\right)$. It shows the influence of every external effect on the multilevel economy. The sum of weights $\sum \varphi_{i}=1.0$.

This study evaluated the impact of various external effects on economy in order to: (a) identify the level of compliance with high developed advanced knowledge economy, and (b) determine the level of compliance of LES with the requirements of RES in modern knowledge economic conditions. If there is a significant disproportion between these systems, we can conclude that the LES is not able to translate a sufficient volume of new knowledge to the real economy, or the speed of their reception, storage and transformation in the LES is very low. It is not in accordance with the requirements of high developed knowledge economy.

\section{Results of evaluation of knowledge effectiveness}

Thus, based on the analysis of the external effects, we realized real disproportions between LES and RES and between RES and high developed knowledge economies from multilevel point of view, for example: on macro-, mezo-, microeconomic and individual levels. This methodology allows us to determine the acceleration or deceleration of the translation process of new knowledge from the education to the economy. Consequently, the important points of estimation are: (a) the analysis of static index of education potential in new economic conditions; (b) the analysis of external effects, showing the level of compliance of LES with the requirements of RES, for example, such effects as dynamic changes. Thus, on one hand, it is important to determine the volume of knowledge accumulated in LES, which was translated to the RES, and on the other hand, it is necessary to control the frequency (speed) of transmitted knowledge to economy and to consumers.

We believe that the approach to estimate the effectiveness of accumulated and translated knowledge from LES to RES is universal, because: (a) it can be used in the analysis of knowledge effectiveness on any economic level; (b) it is easy to calculate the results obtained in the analytical methodology (for example, growth, or acceleration). It provides the estimation of the system, both in statics and dynamics, and (c) the expert assessment methods allow to aggregate different indicators, make them comparable, and use them in normalized form.

Our assessment methodology of knowledge effectiveness in the real economy allowed calculating of effects which influence the macroeconomic level. All individual indicators, which were used to obtain complex results, are based on statistic data for period from 2010 to 2011 (Regions of Russia. Socioeconomic indicators, 2011). And we could gain next results: $e_{1 m}=0.3 ; e_{2 m}=0.3 ; e_{3 m}=0.4 ; e_{4 m}=0.2$; $e_{5 m}=0.2$. 
Every indicator has its significance $\left(\varphi_{i}\right)$, and the sum of all significances is equal to one $\left(\Sigma \varphi_{i}=1.0\right)$. The significance of every effect is 0.2 . The IKE on the macroeconomic level $\left(V_{m}\right)$ can be defined by the formula (12). It gives us the next result.

$$
V_{m}=\Sigma \varphi_{i} e_{i m}=0.28
$$

\section{Conclusion}

The results (formula 12), which represent measures of effectiveness, were made on the macroeconomic level; they have low values. The maximum level of the indicator $\left(V_{m}\right)$ is equal to one. But our results show us the real knowledge of Russian macroeconomics is insufficient. This situation, in our opinion, can be explained by two facts in the real economy: 1) LES is able to accumulate insufficient volume to new knowledge, and 2) may be, the knowledge that was accumulated in education system is sufficient for real economy, but the intensity of its using in the RES is very low. Consequently, the process of creation of new knowledge in the LES and the process of its implementation in the RES cannot be characterized as an active process. The results carried out based on the study indicate a need to create a new economic model of state management by accumulation, transformation and implementation of knowledge in the triad "LSS - LES - RES" to make more intensive this process and to form more competitive and high developed knowledge economy in Russia.

\section{References}

Dianov, M., Bugakova, N. \& Gelvanovsky, M. (2011). Regiony Rossii. Sotsialno-ekonomicheskiye pokazateli [Regions of Russia. Socio-economic indicators]. Moscow, Russia: Posstat.

Suleymankadieva, A. (2012). Nepreryvnogo obrazovaniya v ekonomike znaniy ( monografiya)

[Lifelong Education at Knowledge Economy (Monograph)]. Saint-Petersburg, Russia: Saint Petersburg State Electrical and Technical University.

Tsiplakova, D. (2010). External Knowledge Effects as Prerequisite for Forming Knowledge Economy. J. Economic sciences, 9(70), pp. 45-48.

Zeng, D. Z. \& Wang, S. (2007). China and Knowledg Economy: Challenges and Opportunities. Policy Research Working Paper. The World Bank, World Bank Institute, No 4223.

Zheng, J. Z. \& Jaideep, A. A. (2009). Multilevel Perspective on Knowledge Transfer: Evidence from the Chinese Automotive Industry. Strategic Management Journal, 30, pp. 959-983.

http://dx.doi.org/10.1002/smj.780 